\title{
Perception versus intake of fruit and vegetables
}

\author{
Percepção versus consumo de \\ frutas e hortaliças
}

\author{
Maria Cecília Ramos de CARVALHO ${ }^{1}$ iD 0000-0002-8947-2121 \\ Mariana Carvalho de MENEZES2 (iD) 0000-0002-3069-7959 \\ Aline Cristine Souza LOPES ${ }^{3}$ (iD) 0000-0001-9782-2606
}

A B S T R A C T

\section{Objective}

To compare perception and intake of fruit and vegetables, and to identify the factors associated with misperception of intake.

\section{Methods}

Cross-sectional study with 3,414 participants of the Health Academy Program from Belo Horizonte (MG), Brazil. Stages of change from Transtheoretical Model were used to evaluate perception of intake, and questions adapted from national surveys were used to assess intake of fruit and vegetables as separate groups. Individuals whose intake and perception were discordant were reclassified in pseudo-maintenance (wrongly believe their intake is adequate) or non-reflective action (wrongly believe their intake is inadequate).

\section{Results}

Insufficient intake of fruit and vegetables and misperception of intake were observed. Pseudo-maintenance was more prevalent, given that $45.1 \%$ of individuals were reclassified in this stage regarding their vegetable intake and $22.9 \%$ regarding fruit. According to multinomial logistic regression, pseudo-maintenance of fruit intake

${ }^{1}$ Universidade Federal de Minas Gerais, Escola de Enfermagem, Pós-Graduação em Nutrição e Saúde. Belo Horizonte, MG, Brasil.

2 Fundação Oswaldo Cruz, Escola Nacional de Saúde Pública Sérgio Arouca. Rio de Janeiro, RJ, Brasil.

3 Universidade Federal de Minas Gerais, Escola de Enfermagem, Departamento de Nutrição e Pós-Graduação em Nutrição e Saúde. Av. Professor Alfredo Balena, 190, Santa Efigênia, 30130-100, Belo Horizonte, MG, Brasil. Correspondência paral Correspondence to: ACS LOPES. E-mail: <alinelopesenf@gmail.com>.

Support: Fundação de Amparo à Pesquisa do Estado de Minas Gerais (Process nº APQ-033376-12, 21618/2013 and PPM00254-15) and Conselho Nacional de Desenvolvimento Científico e Tecnológico (Process n 476686/2013-0).

Como citar este artigo/How to cite this article

Carvalho MCR, Menezes MC, Lopes ACS. Perception versus intake of fruit and vegetables. Rev Nutr. 2018;31(2):221-33.

http://dx.doi.org/10.1590/1678-98652018000200008 
was associated with sex, schooling, food and nutrition security, weight satisfaction, and participation in nutrition interventions; pseudo-maintenance of vegetable intake was associated with schooling and weight satisfaction. Non-reflective action was associated with age.

\section{Conclusion}

An important discordance between perception and intake was found, with emphasis on pseudo-maintenance of vegetable intake. Misperception was associated with different factors regarding fruit and vegetables, including sociodemographic variables, participation in nutrition interventions, and weight satisfaction. These results can contribute to the design of interventions aligned with eating behavior, aimed to empower individuals for their food choices.

Keywords: Feeding behavior. Food consumption. Fruit. Models, theoretical. Vegetables.

\section{RE S U M O}

\section{Objetivo}

Este estudo tem por objetivos comparar a percepção e o consumo de frutas e hortaliças, bem como identificar os fatores associados à percepção equivocada do consumo.

\section{Métodos}

Trata-se de estudo transversal com 3.414 participantes do Programa Academia da Saúde de Belo Horizonte, no estado de Minas Gerais, Brasil. Os estágios de mudança do Modelo Transteórico foram utilizados para investigar a percepção do consumo, bem como foram adaptadas questões de inquérito nacional para avaliar objetivamente o consumo desses alimentos em separado. Indivíduos com consumo e percepção discordantes foram reclassificados em pseudomanutenção (acreditam, equivocadamente, que seu consumo é adequado) ou em ação não-refletiva (acreditam, equivocadamente, que seu consumo é inadequado).

\section{Resultados}

Observou-se ingestão insuficiente de frutas e hortaliças e elevada percepção equivocada do consumo. Pseudomanutenção foi mais prevalente, sendo $45.1 \%$ dos indivíduos reclassificados para o consumo de hortaliças e $22.9 \%$ para frutas. Segundo regressão logística multinomial, foram associados à pseudomanutenção para consumo de frutas: sexo, escolaridade, segurança alimentar e nutricional, satisfação com o peso corporal e participação em intervenções nutricionais; e, para hortaliças, escolaridade e satisfação com o peso corporal. Apenas idade foi significativa para ação não-refletiva.

\section{Conclusão}

Verificou-se elevada discordância entre percepção e consumo, com destaque para hortaliças e reclassificação em pseudomanutenção. A percepção equivocada foi associada a diferentes fatores, incluindo variáveis sociodemográficas, participação em intervenções nutricionais e satisfação com o peso corporal. Tais resultados podem contribuir para o delineamento de intervenções mais alinhadas com o comportamento alimentar, visando o empoderamento dos indivíduos para suas escolhas alimentares.

Palavras-chave: Comportamento alimentar. Consumo de alimentos. Frutas. Modelos teóricos. Verduras.

\section{NTRO D U C TIO N}

Fruit and Vegetables (FV) are part of the Brazilian agrobiodiversity and traditional food culture, which add variety, flavor, and pleasure to the diet [1]. Adequate intake is an important factor for health promotion and maintenance, while insufficient intake contributes to the loss of years of healthy life and higher mortality [2-4]. Despite this, only $24.4 \%$ of the adult Brazilian population consumes the recommended amount of fruit and vegetables [5].

Increased FV intake may be hindered by factors such as family income, level of education, food prices, inadequate access/trade, personal preferences, knowledge, culture, and perceived barriers regarding the intake of these foods [4,6-8], as well as resistance to change eating habits originating from possible discordance between the individuals' perception about their eating 
habits and the actual intake of these foods [9]. In this context, the Transtheoretical Model (TTM) assists in the understanding of eating behavior by evaluating perception and comparing it with intake estimates [10].

The main component of TTM is the Stages of Change (SC) construct, suggesting that behavior changes occur dynamically and in stages, according to different degrees of motivation. The five stages of change (pre-contemplation, contemplation, preparation, action, and maintenance) are obtained from the initial classification of individuals that is carried out by applying an algorithm that can be based on the individuals' perception of their intake (e.g., selfreport: Do you consider your current intake of FV to be adequate?) or by the estimation of food intake (application of nutrition surveys) without, however, contemplating the two aspects simultaneously [11].

Methods that evaluate the individuals' perceptions have become a trend, particularly in large-scale studies such as national surveys, as they allow a simple and fast evaluation [12] based on self-reports, "opinions", "attitudes" or self-assessments of food intake $[11,13]$. This approach is promising as it broadens the understanding of the mechanisms related to behavior change, and it is fundamental that individuals recognize their eating habits and deal with their health conditions [11].

When considering that the classification of SC may be misleading due to the discordance between perception and food intake, Steptoe et al. [14] and Ma et al. [15] proposed two new stages, called Pseudo-Maintenance (PM) and Non-Reflective Action (NRA). PM classifies individuals who believe they have adequate intake but objectively have an inadequate quantitative intake when compared to the recommendations. NRA, however, classifies individuals who have adequate food intake according to the recommendations, but consider it inadequate [16]. The classification of the SC can interfere in the allocation and evolution of individuals during interventions, hence the importance of further investigating it $[16,17]$. However, in spite of its relevance, few studies deal with this issue, addressing mainly the consumption of oils and fats and within specific scenarios, promoting insufficient understanding of the concordance between perception and food intake, which may compromise the effectiveness of nutrition interventions [13,16-18].

Considering the low intake of $\mathrm{FV}$, the possible influence of perception on food intake, and the scarcity of studies investigating the concordance between perception and intake, the aim of this study was to compare the perception of adequate FV intake and the estimated intake of these two food groups, and to identify the factors associated with the misperception (PM and NRA) among participants from the Programa Academia da Saúde (PAS, Health Academy Program) from medium, high or very high vulnerability neighborhoods.

\section{METHODS}

This cross-sectional study was conducted in 18 units of the PAS in Belo Horizonte (MG). This healthcare service is part of the Sistema Único de Saúde (SUS, Unified Health System) and provides guided physical exercise primarily designed for the population in greater social vulnerability, focusing on their empowerment and greater control over the health-disease process [19]. The PAS was chosen for this study because of its unique characteristics concerning health promotion, which are intrinsically related to the intake of $\mathrm{FV}$, its focus on empowerment and autonomy of the participants, and its recent implementation in the SUS. A study conducted on the perception of food intake in this healthcare service found $19.4 \%$ of pseudo-maintenance for FV intake (assessed as a single group) among obese individuals [11].

For the sample process, the 50 units of PAS in the city were analyzed in 2012, of 
which 42 were eligible due to being located in neighborhoods with high or very high health vulnerability (the priority areas for the implementation of PAS in the municipality) [19], with morning operation hours, and that had not participated of nutrition intervention activities in the past two years. Based on simple conglomerate sampling, stratified by the nine administrative regions of the municipality, two units of the PAS of each region were randomly selected, totaling 18 units. Further details on sampling can be found in Menezes et al. [20].

\section{Data collection}

Data were collected between February 2013 and June 2014 by interviewers (postgraduate students, Dietitians, and Nutrition undergraduates) and consistency analyses were conducted during data collection and after tabulation of the data. In order to standardize the data collection process and obtain reliable data, a Field Manual was developed, and the interviewers were trained twice a year (20-hour training, consisting of theoretical and practical activities). In addition, the interviewers of each PAS unit were accompanied by field supervisors who were responsible for productivity and verification of data quality.

The data collection instrument was developed from national surveys and nutrition protocols $[5,21]$ and pre-tested in one PAS unit that did not participate in this study. The instrument included sociodemographic variables, self-reported morbidity, health perception and satisfaction with body weight, eating behavior and FV intake, as well as anthropometric measurements.

Sociodemographic variables included sex, age, marital status, level of education, income, and receiving of government benefits. Food and Nutrition Security (FNS) was investigated using the Escala Brasileira de Insegurança Alimentar (EBIA, Brazilian Food Insecurity Scale) [22], which was validated and adapted for the Brazilian culture.
Diabetes Mellitus (DM) and Arterial Hypertension $(\mathrm{AH})$ were investigated by selfreport. In addition, respondents were asked how they perceived their health status using a Likert-type scale (very bad, bad, fair, good, very good) $[5,23]$, their satisfaction with body weight (satisfied/dissatisfied) [21], and their previous participation in interventions to encourage the intake of FV.

Body weight and height were measured according to Ministry of Health standards in order to calculate Body Mass Index (BMI), which was then distinctly classified for adults and the elderly $[24,25]$.

Regarding eating behavior and food intake, the respondents were first asked about their perception of FV intake, followed by objective questions to estimate intake. To evaluate the stages of change for the intake of $F V_{\text {, }}$ the algorithm proposed by Kristal et al. [26] and adapted in Brazil by Toral et al. [27] was applied. This algorithm allowed the initial classification of each participant in the five stages proposed by the TTM (pre-contemplation, contemplation, preparation, action, and maintenance) according to their perception of adequate FV intake.

Subsequently, the habitual intake of FV was estimated using questions adapted from the Vigilância de Fatores de Risco e Proteção para Doenças Crônicas por Inquérito Telefônico (VIGITEL, Surveillance System for Risk and Protection Factors of Chronic Diseases by Telephone Survey), regarding the frequency of intake (days per week), number of servings consumed (per day), and type of preparation $[5,12]$. The question concerning fruit intake was: "How often do you usually eat fruit?" (categories of response: 1-2 days a week, 3-4 days a week, 5-6 days a week; every day (including Saturdays and Sundays); never; almost never - 1-3 times/month); followed by the question "On an average day, how many servings of fruit do you eat?". Similar questions were used for vegetables. Fruit juice was not considered in the study due to the changes in its 
nutritional properties as there may be addition of water and/or sugar during preparation; loss of vitamins and minerals when not consumed at the time of preparation; and possibility of the juice being strained [12]. During the interview, examples of the usual serving sizes of FV commonly consumed by the population were provided and participants were encouraged to respond in kitchen measures (units, slices, leaves, tablespoons, serving spoons, among others). A previous study of the relative validity of different methods used to evaluate the intake of FV was carried out to corroborate the method of choice. The chosen method was the one that presented the highest correlation with the reference method (24-hour food recall associated with a kitchen measurement kit) [12]. In the same direction, previous studies have shown that the brief evaluation of FV intake is relatively accurate and reliable, with substantial agreement (kappa coefficient $=0.62$ ) [28]; strong correlation $(r 0.60 ; p<0.0001)$ [29]; sensitivity close to $80 \%$ [28,29]; specificity between $54 \%$ [28] and 66\% [29]; and positive predictive value between $66 \%$ and $89 \%$ [28].

Intake was classified as adequate or insufficient in accordance with the recommendation of the World Health Organization (WHO) [4]. Considering that a total of five servings should be interpreted as minimum intake and separate instruction should be provided for fruit and vegetables, the intake of at least three daily servings of each food group was considered adequate [4].

By comparing perception and estimated intake, individuals were reclassified in the stages of change of PM or NRA [16]. Individuals who perceived their intake of $\mathrm{FV}$ as adequate (classified in action and maintenance), but who did not reach the recommendations were reclassified in PM, and those who did not perceive their intake as adequate (classified in pre-contemplation, contemplation and preparation), but met the recommendations, were reclassified in NRA (Figure 1).

\section{Statistical analysis}

The data were tabulated in Microsoft Access software and analyzed in the Statistical Package for the Social Sciences for Windows version 15.0 (SPSS, Inc. Chicago, Illinois, United States of America) and STATA version 11.0 (StataCorp, College Station, Texas, United States of America). For the description of the sample, the frequencies of the qualitative variables were identified, while the quantitative variables were submitted to the Kormogorov-Smirnov test to verify their normality and later described by means and standard deviation values for the variables with normal distribution or median distribution and interquartile range for nonnormal distribution. The Chi-square test was used to compare the frequencies of reclassification according to the adequate or inadequate perception of intake of the individuals, adopting a $p$-value of $<0.05$.

To compare the means of FV intake according to the stages of change, Analyses of Variance (ANOVA) were performed. When significant differences were found $(p<0.05)$, the Scheffe test was used for post-hoc analysis, adopting $p$-values of $<0.005$ and $<0.0023$ when comparing the five stages of the initial classification and the seven reclassification stages, respectively.

To identify the factors associated with the reclassification in the PM and NRA stages, multinomial logistic regression analyses were performed separately for fruit and vegetable intake. Thus, the dependent variables were the "reclassification of fruit intake" and "reclassification of vegetable intake", with the following categories: "maintenance of the classification in the initial SC" (reference category), "reclassification in PM" and "reclassification in NRA" stages. The backward method was used to construct the multiple regression models, with $p<0.20$ in the bivariate analysis and biological plausibility being the criteria used to insert the variables. 


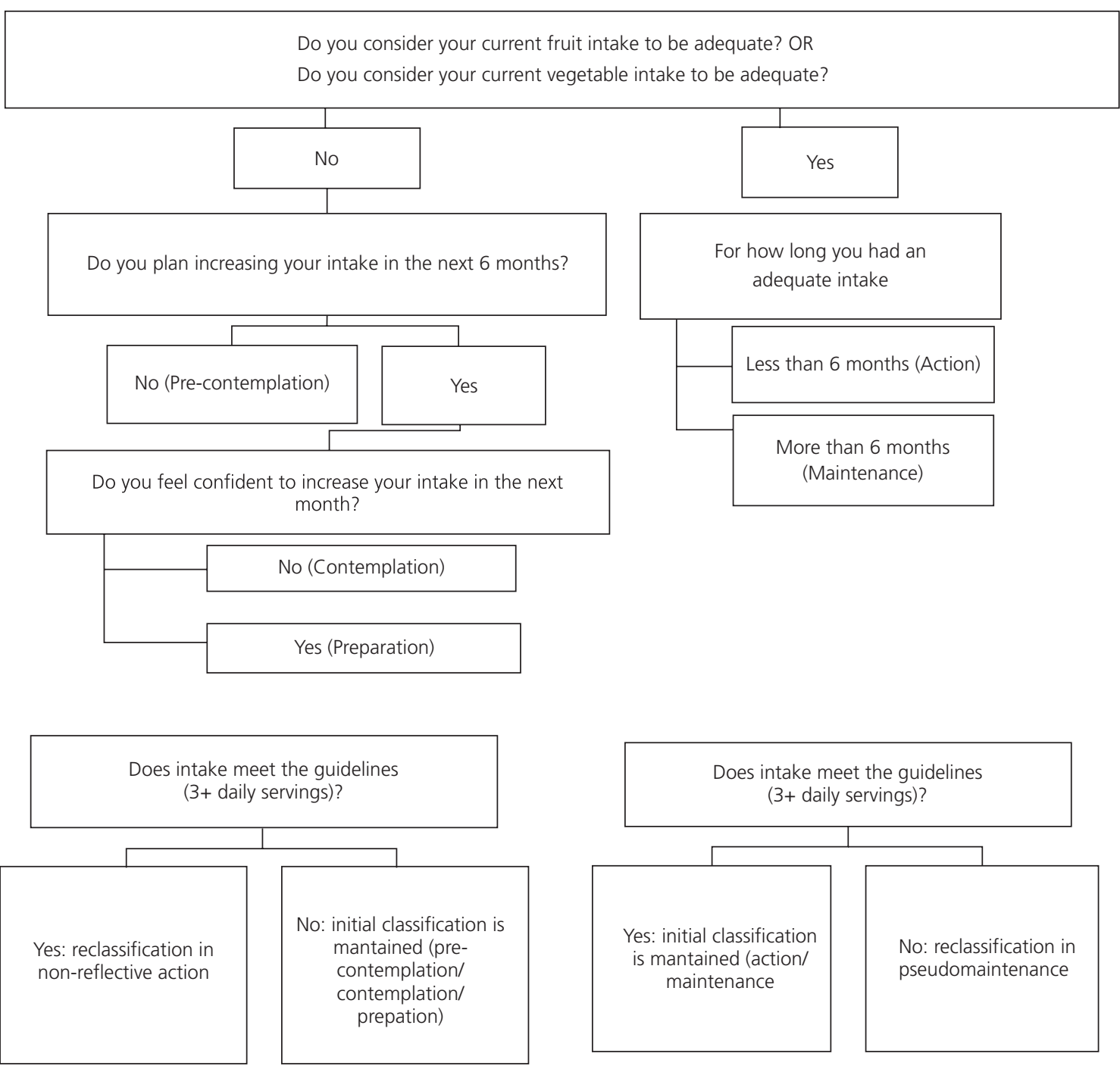

Figure 1. Stages of change algorithm for fruit and vegetable intake and criteria for reclassification in pseudo-maintenance or non-reflective action. Health Academy Program, Belo Horizonte (MG), 2014.

The explanatory variables with p-value of $<0.05$ were maintained at the end, and the fitting quality of the models was verified by the fitstat test.

As for the ethical issues, this study is part of a larger research project that was approved by the Institutional Review Boards of the University ( $n^{\circ}$ 0537.0.203.000-11) and the City Hall ( $n^{\circ}$ 0537.0.203.410-11A). The participation of PAS users was voluntary and written informed consent was obtained, in accordance with the current Brazilian legislation.
RE S U L T S

Of 3,763 PAS users, 3,414 participants were interviewed in this study (refusals $=6.3 \%$, exclusions=3.0\%). Most participants were women, with a median age of 58 (49-65) years, low income and level of education, and most respondents were overweight and/or presented arterial hypertension (Table 1).

Most participants were first classified in the stages of action and maintenance, both for fruit and vegetable intake, as most respondents 
Table 1. Sociodemographic and health characteristics of adults and elderly from the Health Academy Program. Belo Horizonte (MG), 2014.

\begin{tabular}{|c|c|c|}
\hline Variables & $n^{*}$ & Values \\
\hline \multicolumn{3}{|l|}{ Sociodemographics } \\
\hline $\operatorname{Sex}(\%)$ & 3,007 & 88.1 \\
\hline Women & 407 & 11.9 \\
\hline \multicolumn{3}{|l|}{ Men } \\
\hline \multicolumn{3}{|l|}{ Marital status (\%) } \\
\hline Married/consensual union & 2,102 & 61.6 \\
\hline Single/divorced/widowed & 1,311 & 38.4 \\
\hline Age $\left[\right.$ median $\left.\left(P_{25}-P_{75}\right)\right]$ & 3,414 & $58(49-65)$ \\
\hline Per capita income $(R \$)\left[\text { median }\left(P_{25}-P_{75}\right)\right]^{* *}$ & 3,116 & $678.00(424.00-1.000 .00)$ \\
\hline Benefits received $(\%)^{* * *}$ & 164 & 4.8 \\
\hline Years of education [median $\left(\mathrm{P}_{25}-\mathrm{P}_{75}\right)$ ] & 3,414 & $7(4-11)$ \\
\hline \multicolumn{3}{|l|}{ Schooling (\%) } \\
\hline Up to 4 years & 1,291 & 37.8 \\
\hline $5-8$ years & 828 & 24.3 \\
\hline 9 years or more & 1,295 & 37.9 \\
\hline \multicolumn{3}{|l|}{ Health conditions (\%) } \\
\hline Overweight & 2,026 & 59.3 \\
\hline Arterial hypertension & 1,814 & 53.2 \\
\hline Diabetes mellitus & 576 & 16.9 \\
\hline \multicolumn{3}{|l|}{ Perception of health status (\%) } \\
\hline Very bad/bad & 107 & 3.1 \\
\hline Regular & 859 & 25.2 \\
\hline Good/very good & 2,447 & 71.7 \\
\hline \multicolumn{3}{|l|}{ Satisfaction with body weight (\%) } \\
\hline Dissatisfied & 1,913 & 56.1 \\
\hline Satisfied & 1,500 & 43.9 \\
\hline
\end{tabular}

Note: "Number of valid responses or number of individuals in each category. ${ }^{* *}$ Values of minimum wage at the time of data collection: $R \$ 678,00$ (approximately USD 339,85; year: 2013) and R\$724,00 (approximately USD 301,67; year: 2014). ${ }^{* * *}$ Emergency relief, gas stamps, or other government benefits.

perceived their intake of fruit and/or vegetables as adequate. However, the objective assessment identified insufficient intake ( $<3$ servings/day) of fruit and vegetables corresponding to $62.3 \%$ $(n=2,120)$ and $67.3 \%(n=2,296)$ of respondents, respectively.

From these results, the individuals were reclassified in the PM and NRA stages, owing to the discordance between their perception and their estimated intake of FV. For fruit intake, $22.9 \%(n=783)$ of individuals were in the PM stage and $7.5 \%(n=255)$ in the NRA stage; for vegetables, these values were $45.1 \%(n=1,539)$ and $4.7 \%(n=162)$, respectively (Figure 2$)$.

Among the individuals who perceived their fruit intake as adequate, $42.8 \%(n=782)$ were reclassified in PM; among those who perceived it as inadequate, only $16.2 \%(n=256)$ 


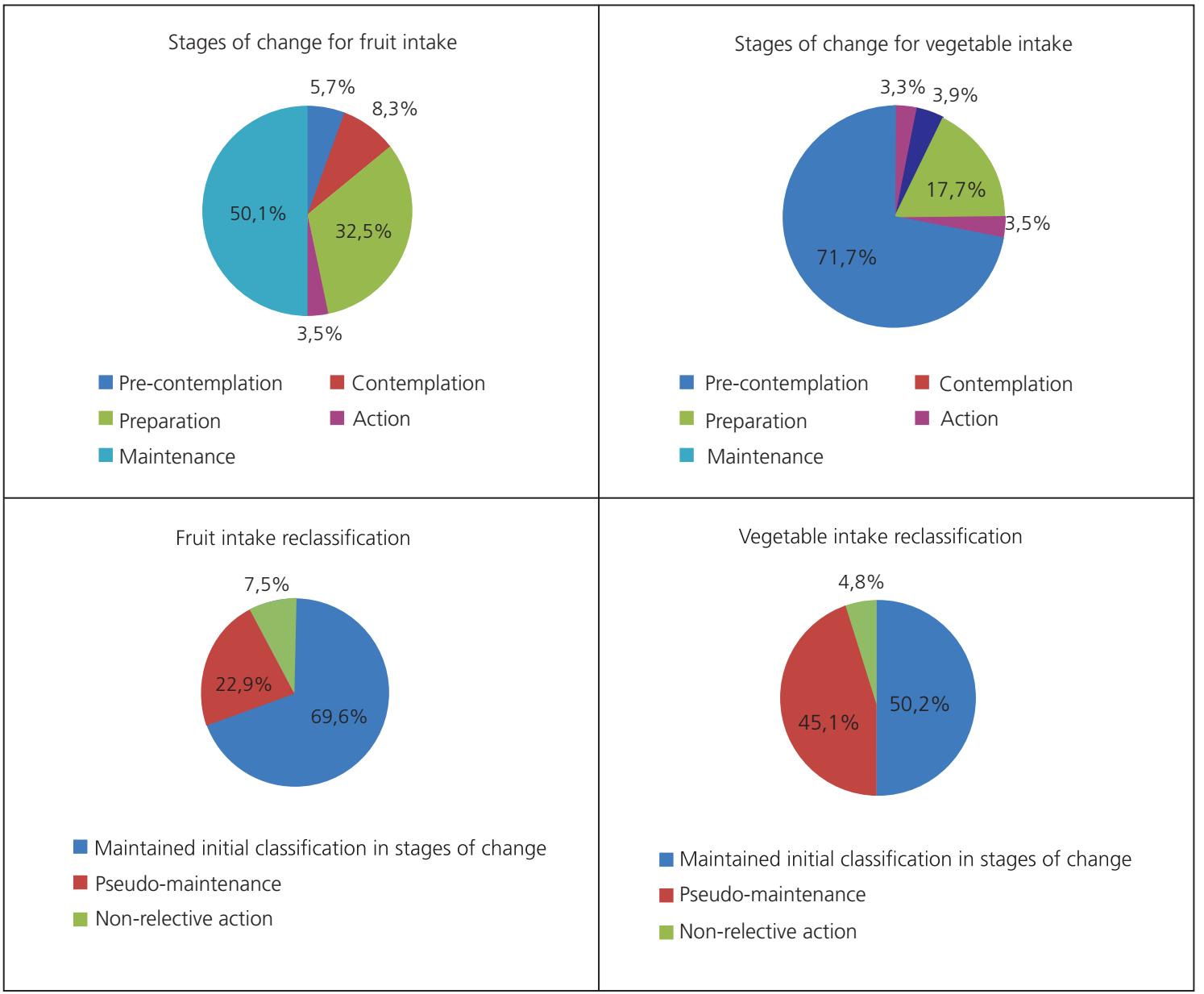

Figure 2. Description of the stages of change for fruit and vegetable intake among adults and elderly according to the initial classification and reclassification. Health Academy Program, Belo Horizonte (MG), 2014.

were reclassified in NRA $(p<0.001)$. For vegetables, these values were $60.1 \%(n=1.540)$ and $18.9 \%$ $(n=161)$ for PM and NRA, respectively $(p<0.001)$.

Table 2 shows the intake of FV according to the classifications in the stages of change. An increase trend of the FV intake was found in the progression to higher stages of action and maintenance. The initial stages (precontemplation, contemplation, preparation) present lower intake of $\mathrm{FV}$ than the more advanced stages (action and maintenance); FV intake in the pseudo-maintenance stage was comparable to the initial stages and the nonreflective action stage was similar to the more advanced stages.
The multinomial logistic regression models showed associations among different variables and the reclassification in PM for fruit and vegetable intake: male sex (fruit: $\mathrm{OR}=1.33$, 1.05-1.69), higher level of education ( $\geq 9$ years) (fruit: $\mathrm{OR}=0.73,0.61-0.88$, vegetables: $\mathrm{OR}=0.86$, $0.74-0.99$ ), food and nutrition security (fruit: $\mathrm{OR}=1.32$, 1.11-1.58), satisfaction with body weight (fruit: $O R=1.44,1.21-1.70$, vegetables: $\mathrm{OR}=1.23,1.07-1.42$ ) and prior participation in interventions to encourage FV intake (fruit: $\mathrm{OR}=0.82$, 0.68-0.99). On the other hand, the reclassification in NRA was only associated with older age ( $\geq 60$ years) (fruit: $O R=1.33,1.01-1.75$ ) (Table 3). 
Table 2. Fruit and vegetable intake (in servings) among adults and elderly according to the stages of change, in accordance with ANOVA. Health Academy Program, Belo Horizonte (MG), 2014.

\begin{tabular}{|c|c|c|c|c|}
\hline \multirow{2}{*}{ Stages of Change } & \multicolumn{2}{|c|}{ Fruit servings (mean $\pm S D$ ) } & \multicolumn{2}{|c|}{ Vegetable servings (mean \pm SD) } \\
\hline & Initial classification & Reclassification & Initial classification & Reclassificaton \\
\hline Pre-contemplation & $2.03 \pm 1.56^{\text {a.b }}$ & $1.65 \pm 1.19^{a}$ & $2.19 \pm 1.22^{\mathrm{a}}$ & $1.90 \pm 0.93^{a}$ \\
\hline Contemplation & $1.96 \pm 1.00^{\mathrm{a}}$ & $1.79 \pm 0.93^{a}$ & $2.51 \pm 1.16^{\text {a.b.c }}$ & $2.22 \pm 0.95^{a}$ \\
\hline Preparation & $2.07 \pm 1.06^{\mathbf{a . b}}$ & $1.79 \pm 0.82^{\mathrm{a}}$ & $2.64 \pm 1.26^{a \cdot b}$ & $2.33 \pm 0.99^{a}$ \\
\hline Action & $2.51 \pm 1.10^{\text {b.c }}$ & $3.50 \pm 0.77^{\mathbf{b}}$ & $3.10 \pm 1.68^{\text {b.c }}$ & $3.95 \pm 1.24^{\mathbf{b}}$ \\
\hline Maintenance & $2.93 \pm 1.32^{c}$ & $3.58 \pm 1.22^{\mathbf{b}}$ & $2.98 \pm 1.41^{c}$ & $3.99 \pm 1.41^{\mathbf{b}}$ \\
\hline Pseudo-maintenance & - & $2.01 \pm 0.81^{a}$ & - & $2.33 \pm 0.98^{a}$ \\
\hline Non-reflective action & - & $3.41 \pm 1.16^{\mathbf{b}}$ & - & $3.84 \pm 1.40^{\mathbf{b}}$ \\
\hline
\end{tabular}

Note: ANOVA $(p<0,05)$; followed by Scheffe test, $p<0.005$ (Initial Classification) and $p<0.0023$ (reclassification).

Different letters in the same column indicate a statistically significant difference. SD: Standard Deviation.

Table 3. Factors associated to the misperception of fruit and vegetable intake among adults and elderly according to multinomial logistic regression. Health Academy Program. Belo Horizonte, (MG), 2014.

\begin{tabular}{|c|c|c|c|c|}
\hline \multirow{3}{*}{ Variáveis } & \multicolumn{2}{|c|}{ Fruit } & \multicolumn{2}{|c|}{ Vegetables } \\
\hline & PM & NRA & PM & NRA \\
\hline & OR $(95 \% \mathrm{Cl})^{*}$ & OR $(95 \% \mathrm{Cl})$ & OR $(95 \% \mathrm{Cl})$ & OR $(95 \% \mathrm{Cl})$ \\
\hline \multicolumn{5}{|l|}{ Sex } \\
\hline Women & 1 & 1 & 1 & 1 \\
\hline Men & $1.33(1.05-1.69)$ & $0.76(0.48-1.19)$ & $0.94(0.75-1.16)$ & $0.90(0.53-1.53)$ \\
\hline \multicolumn{5}{|l|}{ Age group } \\
\hline Adult (20-59 years) & 1 & 1 & 1 & 1 \\
\hline Elderly ( $\geq 60$ years) & $1.06(0.89-1.26)$ & $1.33(1.01-1.75)$ & $1.10(0.95-1.27)$ & $0.79(0.55-1.12)$ \\
\hline \multicolumn{5}{|l|}{ Education } \\
\hline Less than 8 years & 1 & 1 & 1 & 1 \\
\hline 9 years or more & $0.73(0.61-0.88)$ & $0.76(0.58-1.02)$ & $0.86(0.74-0.99)$ & $0.97(0.69-1.36)$ \\
\hline \multicolumn{5}{|c|}{ Satisfaction with body weight } \\
\hline Dissatisfied & 1 & 1 & 1 & 1 \\
\hline Satisfied & $1.44(1.21-1.70)$ & $0.80(0.61-1.05)$ & $1.23(1.07-1.42)$ & $0.89(0.63-1.24)$ \\
\hline \multicolumn{5}{|l|}{ FNS situation } \\
\hline Insecurity & 1 & 1 & ** & ** \\
\hline Security & $1.32(1.11-1.58)$ & $0.96(0.72-1.28)$ & & \\
\hline \multicolumn{5}{|c|}{ Practices to promote FV intake } \\
\hline No & 1 & 1 & ** & ** \\
\hline Yes & $0.82(0.68-0.99)$ & $0.96(0.72-1.28)$ & & \\
\hline
\end{tabular}

Note: ${ }^{*} \mathrm{OR}(95 \% \mathrm{CI})=$ odds ratio and $95 \%$ Confidence Interval. ${ }^{* *} P$-value $>0.200$ in bivariate analysis. Reference category of the outcome variable: maintained initial classification in stages of change.

PM: Pseudo-Maintenance; NRA: Non-Reflective Action; FNS: Food and Nutrition Security. 


\section{DISCUSSION}

The hypothesis of possible misperception of FV intake was confirmed. A great number of individuals were placed in the PM stage, despite their insufficient intake of these foods. This positive misperception was associated with sociodemographic and health factors, as well as participation in nutrition activities, which reinforces the importance of considering the characteristics of individuals in the design and assessment of the interventions in order to obtain more robust results.

The literature points to associations between low FV intake and increased risk of cardiovascular disease (convincing evidence) and cancer (probable evidence) [3], thus being an important dietary risk factor for loss of healthy life years and premature mortality [2], which indicates the need for knowledge and intervention concerning intake of fruit and vegetables.

Discordance between perception and estimated intake of FV was more frequent among individuals who perceived their intake as adequate (PM), both for fruit and vegetables; these results are in agreement with the international literature [30]. As for national investigations, only two studies that assessed the reclassification in $\mathrm{PM}$ and/or NRA for FV intake were found $[11,16]$. However, the comparison of the results with the present study proved to be inadequate due to the different groups studied and methodologies used to classify and reclassify the stages of change, which reveals the lack of reproducibility of current national studies in this field.

The misperception of food intake, particularly in relation to PM, may result from an optimistic bias in self-assessment. The optimistic bias may derive from the different ways individuals evaluate their food intake. Individuals can compare their intake with themselves, their peers, or the nutritional guidelines. If individuals compare their current food intake with past habits, small modifications may lead them to believe that the current intake is adequate, even if objectively there is still need for changes [16]. On the other hand, when comparing themselves to their peers, individuals may believe that their intake is adequate when in fact it is only less inadequate [9]. When individuals compare their intake to the nutritional guidelines, they may have difficulties due to poor understanding of the recommendations when considering food diversity and serving sizes, for example. In addition, the constant dissemination of the importance of healthy eating, particularly by the mass media, can also lead the individual to provide socially acceptable responses [31,32]. In all situations mentioned, an optimistic bias can be present, leading to a misperception of one's food intake, which may, in turn, affect interventions that encourage healthy food intake such as fruit and vegetables.

The misperception was lower for fruit intake when compared to vegetables, which was similar to the results found by Lechner et al. [30] and Glasson et al. [6]. These differences possibly arise from the way individuals consume and evaluate intake of these foods. Fruit appear to be more easily quantified because they have a regular shape and are generally consumed in isolation, and their intake recommendations are probably better known [7,12], which contributes to a more consistent perception of actual intake. On the other hand, it is more difficult to determine the serving of vegetables as they are normally ingredients of culinary preparations [12]. Thus, although FV intake is generally assessed together, it is possible that the population has different behaviors regarding these food groups. Therefore, they should be investigated separately and the barriers and facilitators concerning their intake must be taken into consideration [8,33].

In view of the high prevalence of misperception regarding the intake of $\mathrm{FV}$, the factors associated with these findings were investigated. Men tend to have more 
optimistic perceptions of their eating habits [9], while the perceptions of older people may be negatively influenced by cognitive impairment or mental health-related issues [34]. A high degree in education and previous participation in interventions that encourage FV intake, in turn, may favor knowledge and understanding of the recommendations and consequently a more consistent perception of intake, which reinforces the need to plan, implement, and evaluate practices that promote FV intake. Given that the health sector is not responsible for promoting an increase in the level of education, intersectoral policies and actions, as well as nutrition interventions especially adapted for the target population with clear and comprehensible information for the population in general are necessary [6].

A situation of FNS indicates, among other aspects, the ability to purchase food, including fruit and vegetables [22], which can lead individuals to believe that their ability to buy FV results in adequate intake [31]. On the other hand, food and nutrition insecurity demands structural interventions that go beyond educational actions to promote adequate FV intake and awareness of one's intake [22]. Satisfaction with body weight can probably be related to a more optimistic view of individuals concerning their diet [35].

The strengths of this study include its robust methodology, the size and representativeness of the sample, and its innovative results. Its pioneering character is reaffirmed, regarding the investigation of eating behavior of adults and elderly, as it addresses fruit and vegetables separately for investigating eating behavior and identifies different factors that are associated to the reclassification in PM and NRA. All these issues should be further investigated in the international literature.

Further studies should conduct the reclassification of the stages (recognizing, therefore, the possibility of misperceived food intake), since individuals with misperceptions and highly optimistic views (reclassified in PM) may have greater difficulty changing their habits, either because they do not recognize the inadequacies and are less motivated to change, or because the interventions they usually receive are directed at action and maintenance groups and they remain unaware of their insufficient FV intake [16]. Considering the current overweight situation of the adult Brazilian population and the possible contribution of higher FV intake (which also contributes to the lower intake of ultraprocessed foods) for reducing or maintaining body weight $[3,5]$, this suggestion becomes more relevant for intervention studies. By using the method based on the initial classification and the reclassification for the allocation of individuals in the intervention groups, further studies will be able to verify if there is a real need for differentiated approaches for the PM and NRA stages.

Another strength of the present study was the order of the sections on the assessment of behavior and food intake in the data collection instrument, which favored the identification of misperceptions. If the food intake assessment had been performed before the classification of the stages of change, individuals would be induced to reflect on their intake, which could affect the validity of their responses to the algorithm. We suggest that future studies use the same sequence to obtain more reliable results.

One limitation of the study was the difficulty participants had in adequately quantifying the servings of vegetables consumed as part of mixed dishes, which is a common habit of the Brazilian population [12]. Another limitation refers to the cross-sectional design that prevents causal inference. In addition, the sample presents little socioeconomic variability, which was expected since the units of PAS are preferentially located in areas of greater social vulnerability. Thus, the results should be extrapolated considering the low socioeconomic status of the population studied. 
The investigation of the concordance between perception and food intake, as carried out in this study, may favor the design of more effective nutrition interventions, particularly those based on the Transtheoretical Model or those that consider the eating behavior in its design.

\section{CONCLUSION}

This study revealed a high prevalence of misperceptions, especially considering the intake of vegetables and the reclassification in PM, and the factors associated with this incoherent relationship between perception and intake were also identified. These results may contribute to the design of interventions that are more aligned with eating behaviors, aiming to empower individuals for their food choices.

In agreement with the results of this study, we recommend the investigation of the evolution of perception and intake of FV after individuals participate in nutrition interventions. Thus, we expect to identify if there is a different evolution among individuals with misperception in comparison with others. The intention of the research group is to conduct this investigation in the near future.

\section{CONTRIBUTORS}

ACS LOPES was responsible for the design, coordination and fundraising for the research, and critical review of the manuscript. MC MENEZES conducted the data collection, assisted in data analysis, interpretation of the results, and critical review of the manuscript. MCR CARVALHO was responsible for the data analysis, interpretation of results and writing of the manuscript. All authors approved the final version of the manuscript.

\section{REFERE N CES}

1. Ministério da Saúde (Brasil). Alimentos regionais brasileiros. 2a ed. Brasília: Ministério da Saúde; 2015.
2. Forouzanfar $\mathrm{MH}$, Alexander $\mathrm{L}$, Anderson $\mathrm{HR}$, Bachman VF, Biryukov S, Brauer $M$, et al. Global, regional, and national comparative risk assessment of 79 behavioural, environmental and occupational, and metabolic risks or clusters of risks in 188 countries, 1990-2013: A systematic analysis for the Global Burden of Disease Study 2013. Lancet. 2015;386(10010):2287-323.

3. Boeing $\mathrm{H}$, Bechthold $\mathrm{A}$, Bub $A$, Ellinger $\mathrm{S}$, Haller $\mathrm{D}$, Kroke A, et al. Critical review: Vegetables and fruit in the prevention of chronic diseases. Eur J Nutr. 2012;51(6):637-63.

4. World Health Organization, Food and Agriculture Organization. Fruit and vegetables for health. Report of a Joint FAONHO Workshop, 1-3 September, 2004. Japan, Kobe; 2005.

5. Ministério da Saúde (Brasil). Vigitel Brasil 2016: vigilância de fatores de risco e proteção para doenças crônicas por inquérito telefônico. Brasília: Ministério da Saúde; 2017.

6. Glasson C, Chapman K, James E. Fruit and vegetables should be targeted separately in health promotion programmes: Differences in consumption levels, barriers, knowledge and stages of readiness for change. Public Health Nutr. 2011;14(4):694-701.

7. Figueira TR. Consumo de frutas e hortaliças entre usuários do Programa Academia da Saúde em Belo Horizonte, MG: contribuições para a educação em saúde. Belo Horizonte: Fundação Oswaldo Cruz; 2015

8. Figueira TR, Lopes ACS, Modena CM. Barreiras e fatores promotores do consumo de frutas e hortaliças entre usuários do Programa Academia da Saúde. Rev Nutr. 2016;29(1):85-5. http://dx. doi.org/10.1590/1678-98652016000100009

9. Sproesser G, Klusmann V, Schupp HT, Renner B. Comparative optimism about healthy eating. Appetite. 2015;90:212-8.

10. Prochaska JO, Norcross JC, DiClemente CC. Applying the stages of change. Psychother Austr. 2013;19(2):10-5.

11. Bedeschi LB, Lopes ACS, Santos LC. Stages of change and factors associated with misperceived eating behavior in obese individuals. Rev Nutr. 2016;29(1):33-42. http://dx.doi.org/10.15 90/167 8-98652016000100004

12. Lopes MS, Santos LCD, Lopes ACS, Abreu MNS. Comparison between two assessment tools for fruit and vegetable intake relative to the $24-\mathrm{h}$ recall. Nutrition. 2017;38:34-40.

13. Moreira RAM, Santos LC, Menezes MC, Lopes ACS. Eating behavior toward oil and fat consumption versus dietary fat intake. Rev Nutr. 
2014;27(4):447-57. http://dx.doi.org/10.15 90/14 15-52732014000400006

14. Steptoe A, Wijetunge S, Doherty S, Wardle J. Stages of change for dietary fat reduction: Associations with food intake, decisional balance and motives for food choice. Health Educ J. 1996;55(1):108-23.

15. Ma J, Betts NM, Horacek T, Georgiou C, White A. Assessing stages of change for fruit and vegetable intake in young adults: A combination of traditional staging algorithms and food-frequency questionnaires. Health Educ Res. 2003;18(2):22436.

16. Toral N, Slater B. Perception of eating practices and stages of change among Brazilian adolescents. Prev Med. 2009;48(3):279-83.

17. Menezes MC, Mingoti SA, Mendonça RD, Lopes ACS. Mistaken perception of lipid intake and its effects: A randomized trial. BMC Nutr. 2017; $3(1): 1-9$.

18. Plotnikoff RC, Hotz SB, Johnson ST, Hansen JS, Birkett NJ, Leonard LE. Readiness to shop for lowfat foods: A population study. J Am Diet Assoc. 2009;109(8):1392-7.

19. Costa BVL, Mendonça RD, Santos LCD, Peixoto SV, Alves M, Lopes ACS. City Academy: A health promotion service in the healthcare network of the Unified Health System. Ciênc Saúde Coletiva. 2013;18(1):95-102.

20. Menezes MC, Costa BV, Oliveira CD, Lopes AC. Local food environment and fruit and vegetable consumption: An ecological study. Prev Med Rep. 2017;5:13-20.

21. Lopes ACS, Ferreira AD, Santos LC. Atendimento nutricional na Atenção Primária à Saúde: proposição de protocolos. Nutr Pauta. 2010;101:40-4.

22. Segall-Corrêa AM, Marin-Leon L. A Segurança Alimentar no Brasil: proposição e usos da Escala Brasileira de Medida da Insegurança Alimentar (EBIA) de 2003 a 2009. Seg Alim Nutr. 2009;16(2):1-19.

23. Instituto Brasileiro de Geografia e Estatística. Pesquisa Nacional de Saúde 2013: percepção do estado de saúde, estilos de vida e doenças crônicas. Rio de Janeiro: IBGE; 2014.

24. Ministério da Saúde (Brasil). Orientações para a coleta e análise de dados antropométricos em serviços de saúde: Norma Técnica do Sistema de Vigilância Alimentar e Nutricional: SISVAN. Brasília: Ministério da Saúde; 2011.
25. Nutrition Screening Initiative. Nutrition interventions manual for professionals caring for older Americans. Washington (DC): NSI; 1992.

26. Kristal AR, Glanz K, Curry SJ, Patterson RE. How can stages of change be best used in dietary interventions? J Am Diet Assoc. 1999;99(6):679-84.

27. Toral N, Slater B, Cintra IDP, Fisberg M. Comportamento alimentar de adolescentes em relação ao consumo de frutas e verduras. Rev Nutr. 2006;19(3):331-40. http://dx.doi.org/10.1590/s1 415-52732006000300004

28. Mendes LL, Campos SF, Malta DC, Bernal RT, de Sa NN, Velasquez-Melendez G. Validity and reliability of foods and beverages intake obtained by telephone survey in Belo Horizonte, Brazil. Rev Bras Epidemiol. 2011;14(Suppl 1):80-9.

29. Godin G, Belanger-Gravel A, Paradis AM, Vohl MC, Perusse L. A simple method to assess fruit and vegetable intake among obese and non-obese individuals. Can J Public Health. 2008;99(6):494-8.

30. Lechner L, Brug J, De Vries H, Van Assema P, Mudde A. Stages of change for fruit, vegetable and fat intake: Consequences of misconception. Health Educ Res. 1998;13(1):1-11.

31. Moreira CC, Moreira EAM, Fiates GMR. Perceived purchase of healthy foods is associated with regular consumption of fruits and vegetables. J Nutr Educ Behav. 2015;47(3):248-52.

32. Rooney C, McKinley MC, Appleton KM, Young IS, McGrath AJ, Draffin CR, et al. How much is "5-a-day"? A qualitative investigation into consumer understanding of fruit and vegetable intake guidelines. J Hum Nutr Diet. 2017;30(1):105-13.

33. Appleton KM, Hemingway A, Saulais L, Dinnella C, Monteleone E, Depezay L, et al. Increasing vegetable intakes: Rationale and systematic review of published interventions. Eur J Nutr. 2016;55(3):869-96.

34. Greene GW, Fey-Yensan N, Padula C, Rossi SR, Rossi JS, Clark PG. Change in fruit and vegetable intake over 24 months in older adults: Results of the SENIOR project intervention. Gerontologist. 2008;48(3):378-87.

35. Santos EMC, Tassitano RM, Nascimento WMFD, Petribú MMV, Cabral PC. Body satisfaction and associated factors among high school students. Rev Paul Pediatr. 2011;29(2):214-23.

Received: July 7, 2017

Final version: November 6, 2017

Approved: February 20, 2018 


\section{ERRATUM}

In article "Perception versus intake of fruit and vegetables" with DOI: 10.1590/1678-986 52018000200008 published in Revista de Nutrição, 31(2):221-233, on page 228:

Where is read: The colors of the graph "Stages of change for vegetable intake".

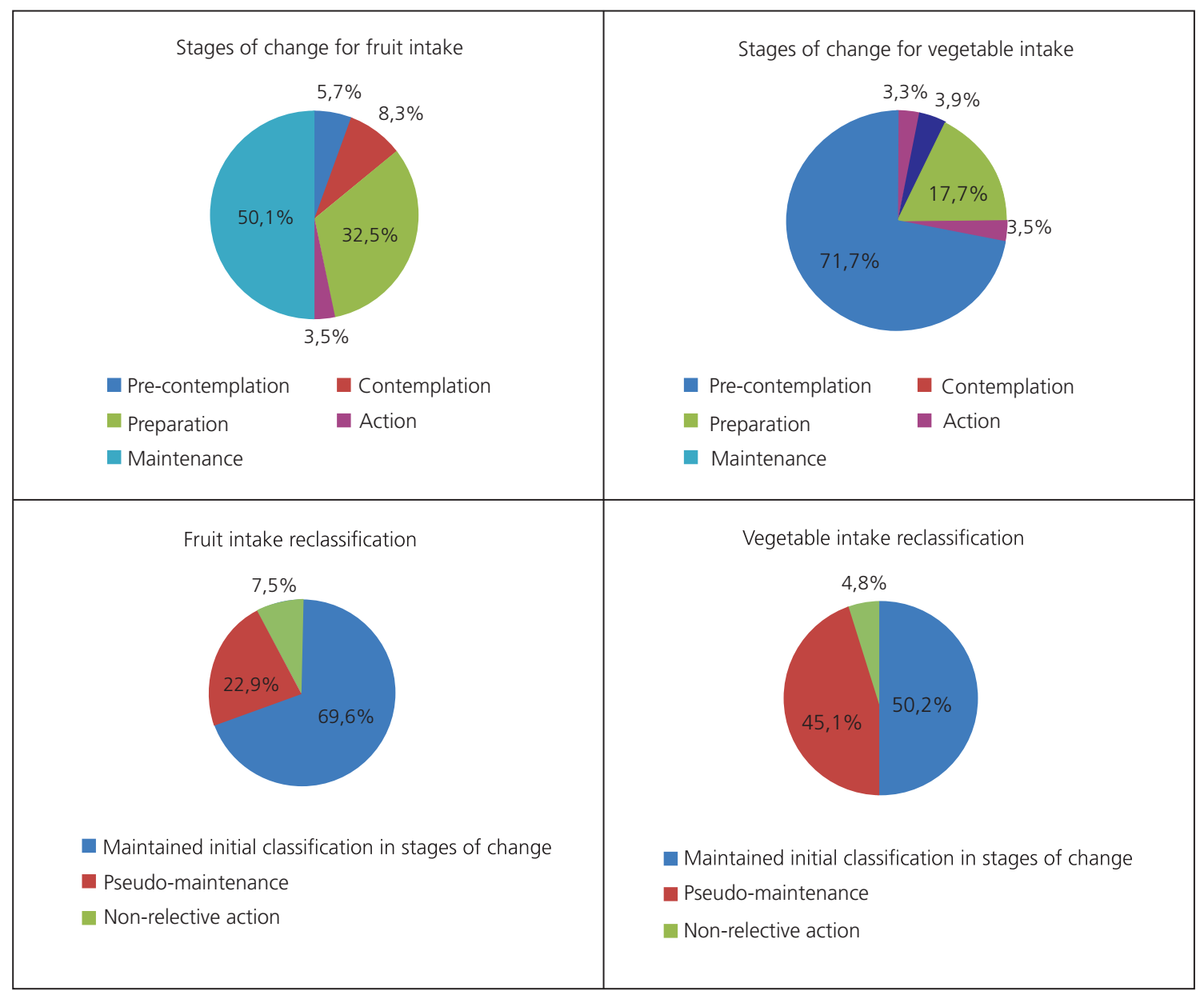

Figure 2. Description of the stages of change for fruit and vegetable intake among adults and elderly according to the initial classification and reclassification. Health Academy Program, Belo Horizonte (MG), 2014. 
Should read: The colors of the graph "Stages of change for vegetable intake".

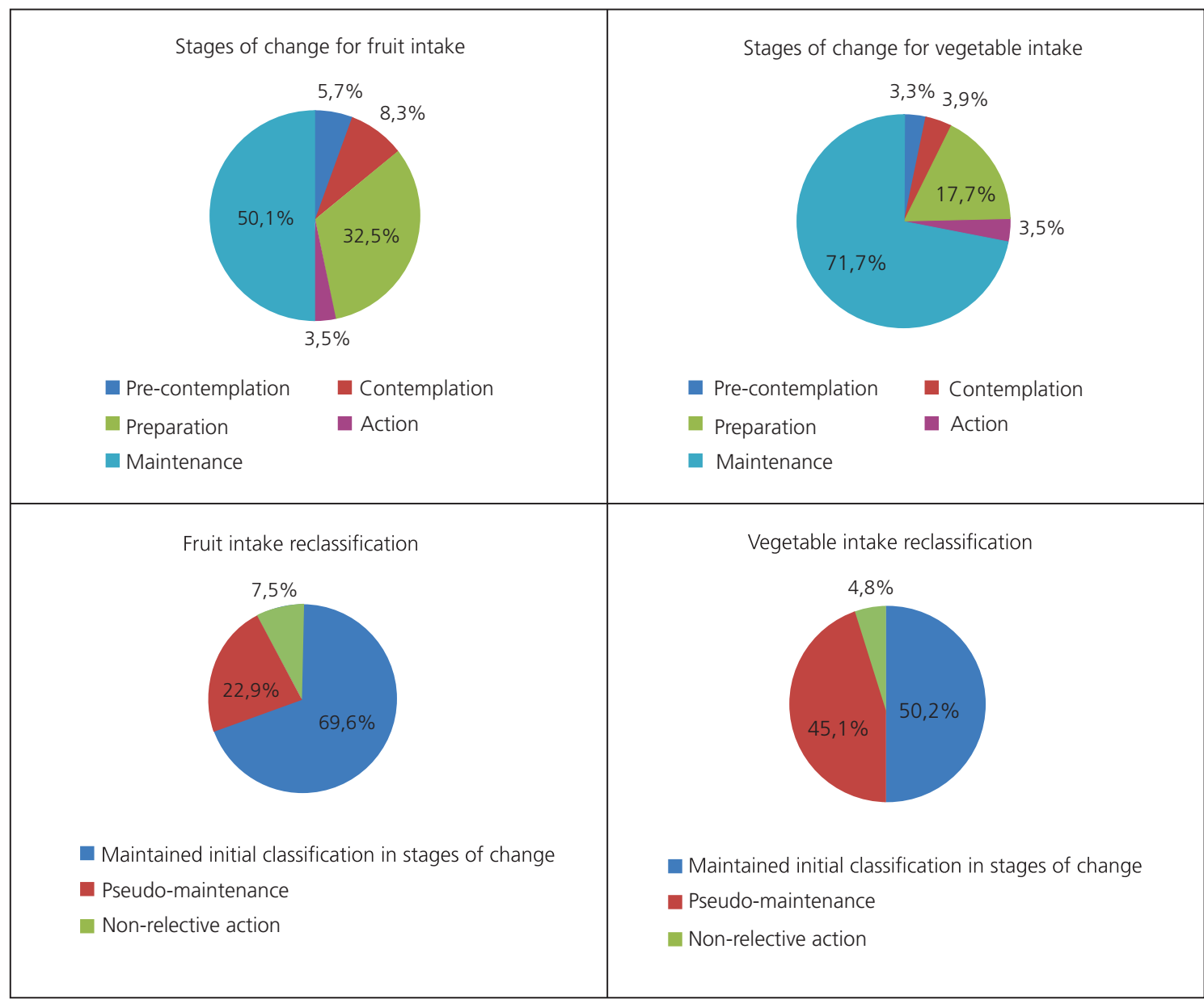

Figure 2. Description of the stages of change for fruit and vegetable intake among adults and elderly according to the initial classification and reclassification. Health Academy Program, Belo Horizonte (MG), 2014. 